\title{
A multirheology ice model: Formulation and application to the Greenland ice sheet
}

\author{
Diandong Ren, ${ }^{1,2}$ Rong Fu, ${ }^{1}$ Lance M. Leslie, ${ }^{2,3}$ David J. Karoly, ${ }^{4}$ Jianli Chen, ${ }^{1,5}$ \\ and Clark Wilson ${ }^{1}$ \\ Received 6 August 2010; revised 10 December 2010; accepted 3 January 2011; published 9 March 2011.
}

[1] Accurate prediction of future sea level rises requires models which can reproduce recent observed change in ice sheet behavior. This study describes a new multiphase, multiple-rheology ice dynamics model (SEGMENT-ice), which is used to examine Greenland ice sheet (GrIS) responses both to past and to possible future warming climate conditions. When applied to the GrIS, SEGMENT-ice exhibits skill in reproducing the mass loss rate derived from the Gravity Recovery and Climate Experiment (GRACE), the interferometric synthetic aperture radar (InSAR) measured surface flow speed, and the microwave remotely sensed surface melt area over the past decade. When forced by the NCEP/NCAR reanalysis atmospheric parameters, the ice model simulates closely the GrIS mass loss rate obtained from GRACE. An increase of summer maximum melt area extent (SME) is indicative of an expansion of the ablation zone. The modeled SME from 1979 to 2006 also simulates well the observed interannual variability of SME, with a high correlation of 0.88 between the two time series. The geographical distributions of the modeled and observed SME also agree well. Comparison of modeled and observed velocity over three regions, covering the west, northeast, and north sides of the GrIS, respectively, indicates a satisfactory model performance in delineating flow direction and magnitudes for regions with flow speed less than $500 \mathrm{~m} / \mathrm{y}$, with no region-specific systematic errors. However, the model cannot simulate extremes in the observations, mainly because it is limited by spatial resolution. The SEGMENT-ice simulations are sufficiently close to the observations to employ the model to project the future behavior of the GrIS. By the end of this century, if the moderate A1B scenario is realized, the total mass loss rate will reach $\sim 220 \mathrm{~km}^{3} / \mathrm{y}$. The ice divergence contribution will be about $60 \%$, outweighing the contribution from surface processes.

Citation: Ren, D., R. Fu, L. M. Leslie, D. J. Karoly, J. Chen, and C. Wilson (2011), A multirheology ice model: Formulation and application to the Greenland ice sheet, J. Geophys. Res., 116, D05112, doi:10.1029/2010JD014855.

\section{Introduction}

[2] Freshwater discharge from land ice is a major contributor to global and regional sea level rise [Greve and Blatter, 2009; Yin et al., 2009; Alley, 2000]. Accurate prediction of future sea level rise requires ice models that can reproduce the recent dramatic changes in ice sheet behavior. Current ice models generally do not capture observed ice

\footnotetext{
${ }^{1}$ Jackson School of Geosciences, University of Texas at Austin, Austin, Texas, USA.

${ }^{2}$ Australian Sustainable Development Institute, Curtin University, Perth, Western Australia, Australia.

${ }^{3}$ School of Meteorology, University of Oklahoma, Norman, Oklahoma, USA.

${ }^{4}$ School of Earth Sciences, University of Melbourne, Melbourne, Victoria, Australia.

${ }^{5}$ Center for Space Research, University of Texas at Austin, Austin, Texas, USA.

Copyright 2011 by the American Geophysical Union. 0148-0227/11/2010JD014855
}

sheet behavior because of simplistic physics and inadequate treatment of key basal and lateral boundary conditions. The IPCC Fourth Assessment Report [Solomon et al., 2007] (http://ipcc-wg1.ucar.edu/wg1/wg1-report.html) mostly uses shallow ice dynamics models which assume that the ice sheet everywhere is in local equilibrium. Such models [e.g., Huybrechts et al., 2004] state that the contribution of ice dynamics to the total ice loss will be moderate (10-20\%) over the 21 st Century and that the mass loss will be dominated $(80-90 \%)$ by surface mass balance. IPCC AR4 explicitly recognizes that "quantitative projections of how much the accelerated ice flow would add (to sea level rise) cannot be made with confidence, owing to limited understanding of the relevant processes" (FAQ subsection 5.1). This study employs a fully three dimensional Navier-Stokes ice dynamics model (SEGMENT-ice) that supports a multirheology. The SEGMENT-ice model is described in detail in Appendix A.

[3] Recently, model projections of the ice sheet contribution to sea level change have been supplemented by new technology that has significantly increased available obser- 
vations [Wouters et al., 2008; Joughin et al., 2008; Chen et al., 2006; Howat et al., 2007; Velicogna and Wahr, 2006]. This expansion of observational capability over the past decade, particularly in airborne/spaceborne remote sensing, has revealed major changes in ice sheet flow and ice mass over time scales ranging from seasons to decades [Chen et al., 2006; Nettles et al., 2008]. Mounting evidence [Van den Broeke et al., 2009] indicates that the IPCC AR4 estimation may be an underestimation of the contribution of the Greenland ice sheet (GrIS henceforth) to sea level changes over the 21 st century.

[4] The ongoing Sea level Response to Ice Sheet Evolution (SeaRISE) project is responsible for archiving various observational ice sheet parameters to verify, modify, and validate ice flow models. Consequently, a narrowing of sea level rise uncertainty is expected in the next IPCC assessment report. Here, a new modeling system, SEGMENT-ice, is introduced, with improved basal sliding physics, a data assimilation capability, and more efficient numerical solution techniques. Many ice dynamics models assume that the ice sheet locally is in equilibrium and omit the convection components of the acceleration terms. Convection terms are referred to in meteorology as "advection" terms, to avoid confusion with thermal and other forms of buoyancygenerated convection. Here the advection terminology is used. SEGMENT-ice retains the advection terms, consistent with the modeling approach adopted by the authors in all of their geofluid flow modeling studies. That is, SEGMENTice employs the full Navier-Stokes equations, although there is no universal agreement at present in the ice modeling community that the inclusion of the advection terms is necessary. Another key feature of SEGMENT-ice is a granular sliding layer between the bottom ice layer and the lithosphere layer, for areas with basal meltwater and those with surface crevasses indicating uneven bed topography. The layer was introduced because of recent developments in granular material rheology [Jop et al., 2006]. It provides a lubricating layer of basal sediments between the ice and the bedrock, enhancing ice flow and acting as a mechanism for large-scale surges [MacAyeal, 1992; Alley et al., 2005] in a warming future world. The thermomechanically coupled ice scheme is implemented as a component of an existing scalable and extensible geofluid model (SEGMENT) described earlier by Ren et al. [2008]. Hence it is referred to as SEGMENT-ice. As outlined in Appendix A, SEGMENT-ice provides prognostic fields of the driving and resistive forces and describes both the flow fields and the evolution of the ice thickness profile. The modeling system is validated against remote sensing measurements of the Greenland ice sheet (GrIS) properties [Ren et al., 2010].

\section{Data}

[5] The GrIS is one of the most studied land ice sheets and SeaRISE provides ice sheet parameters that can be used to verify ice flow model simulations. To simulate the observed GrIS features of the 20th and early 21 st centuries, SEGMENT-ice requires spatially distributed fields of topography and ice thickness and temporally distributed meteorological data.

\subsection{Digital Elevation Map, Geothermal Heat Flux, and Initial Ice Temperature Field}

[6] The ice model requires as initial input both ice thickness and free surface elevation. The modeling was carried out with the 5-km digital elevation map (DEM) for bedrock and ice thickness data [Bamber et al., 2001] over Greenland, from the SeaRISE Web site (http://websrv.cs. umt.edu/isis/index.php). In October 2010, a 1-km DEM has become available and will allow future work to be carried out at higher resolutions.

[7] The total ice volume is $\sim 2.9 \times 10^{6} \mathrm{~km}^{3}$. Owing to the low heat conductivity of ice $\left(2.07 \mathrm{~W} / \mathrm{m} / \mathrm{K}\right.$ at $\left.0^{\circ} \mathrm{C}\right)$ and the higher heat storage capability of ice, effects from an erroneous initial temperature profiles will persist. Unfortunately, in situ measurements of ice profile temperature remain limited over Greenland. Therefore the initial temperature field from a paleoclimate simulation of the Simulation Code for Polythermal Ice Sheets (SICOPOLIS) [Greve, 2000] is used. It covers the entire last glacial-interglacial cycle (150 kyr BP-modern) [Greve, 2005]. Because the existing temperature field is at $20-\mathrm{km}$ resolution, it is interpolated to $5-\mathrm{km}$ resolution using a bilinear interpolation scheme [Burrough and McDonnell, 2004]. The ice sheet temperature regime is controlled by surface energy balance history, ice flow, and the spatial distribution of geothermal heat flux [Greve, 2005; Cuffey et al., 1995; Pollack et al., 1993]. For simulations extending into the future, the geothermal pattern provided by SeaRISE is held constant.

\subsection{NCEP/NCAR Reanalysis Monthly Means}

[8] Coupled ocean-atmospheric general circulation models (CGCMs) do not resolve realistic time series of interannual and decadal climate variations. Thus they cannot be used as climate forcing for our ice model validation against observations on interannual to decadal scales. We use more realistic climate forcing provided by the National Center for Environmental Prediction (NCEP)/NCAR reanalysis [Kalnay et al., 1996]. The reanalysis data are widely used by the climate research community as a surrogate for real observations on large spatial scales. The 20 th century simulations of the CGCMs (20C3M runs in CMIP3) are used to initialize the model; then atmospheric parameters from the NCEP/ NCAR reanalysis data are blended in after 1948. Specifically, the 20C3M monthly output is taken from two recently available high-resolution CGCMs (i.e., MIROC3.2-hires [K-1 Model Developers, 2004] and NCAR-CCSM3 [Collins et al., 2007]) to spin up the ice model. The 1948-2008 segment atmospheric parameters provided by CGCMs are then replaced by the NCEP/NCAR reanalysis monthly mean precipitation, surface air temperature, and surface energy fluxes. Because the time period of the reanalysis data (1948present) encompasses the satellite era (1979-present), ice dynamics models forced/driven by this time series should reproduce the remotely sensed recent significant changes of the GrIS. The atmospheric parameters are linearly downscaled to spatially match the ice geometry data to integrate the ice dynamics model at $5 \mathrm{~km}$ resolution.

[9] The remotely sensed validation data sets, such as the Gravity Recovery and Climate Experiment (GRACE) measured total mass changes, interferometic synthetic aperture 
radar (InSAR) measured surface flow, and SSM/I measured surface melting extent are described below in section 4 .

\section{The Numerical Model}

[10] The numerical model system is described in detail in Appendix A. It has been used in numerous applications, for example as a landslide model [Ren et al., 2010]. It is a continuum-mechanical formulation that uses the stress decomposition of Van der Veen and Whillans [1989]. It is a scalable and extensible geofluid model (referred to as SEGMENT) and has been described by Ren et al. [2008, 2010]. In its extension to ice flow in this study, it incorporates an ice model component and the model system is referred to as SEGMENT-ice. The ice dynamic model includes the full form of the Navier-Stokes equations. Thermodynamic aspects of the model follow primarily the SICOPOLIS formulation [Greve and Hutter, 1995], including its "front-tracking" approach to phase changes. However, there is no consensus over the use of the full Navier-Stokes equations. They are computationally expensive when compared with shallow ice models, which assume a balance of viscous and pressure gradient forces (pgf). For temperate valley glaciers with large aspect ratios and that reside on steep bedrock or are partially submerged under water and for those with particular thermodynamic conditions, it is necessary to use the full Navier-Stokes equations [Zwinger et al., 2007; Zwinger and Moore, 2009; Pattyn, 2003; Pattyn et al., 2008]. At the GrIS margins, fast-flowing ice streams discharge huge amounts of ice into the ocean. Again, the full Navier-Stokes model might be expected to be useful in simulating the ice streams and the surrounding transition zones because of their large aspect ratios. For these reasons, and in anticipation of planned future work at much higher resolutions that allow for modeling of ice sheet calving and other detailed processes $(\sim 1 \mathrm{~km}$ DEM recently have become available), our strategy therefore has been to employ the full Navier-Stokes equations in this relatively lower-resolution study.

\section{Results and Discussion}

[11] For verification against the observed changes of the GrIS during the past decade, the NCEP/NCAR 60-year reanalysis atmospheric parameters are used to force the ice model. In the following, the modeled present (2000) surface velocity field and the summer maximum melt area extend (1979-2007) are examined and the mass loss rate of the GrIS (2002-2008) is compared with remote sensing measurements. Total mass balance consists of surface mass balance, which is affected by meteorological conditions and dynamical balance, which is from flow divergence and convergence. The lack of flow divergence information led to the low IPCC-AR4 estimation of GrIS contribution to seal level rise. It is critical to simulate the ice flow over the entire GrIS.

[12] Recently, seaRISE posted interferometric synthetic aperture radar (InSAR) measured vector velocity [Joughin et al., 2010]. These velocities are compiled from the 5-year observations of the RADARSAT-1 modified Antarctica Mapping Mission, the Canadian Space Agency (CAS). The observations yield a composite map that averages all the observations contained in 2000 and 2005-2008. The map is representative of the early 21 st century speeds. While providing nearly complete coverage, these data sets have gaps over southern Greenland where the acquisition priority for other modes and locations was high. Other gaps are the result of poor coherence between images, typically in areas with high mass turnover, such as in the southeast.

[13] Figure 1 is the modeled present, early 21 st century, surface velocity composed from the horizontal velocity components only, as there are no observed vertical velocity fields. It is compared with the InSAR observed velocity. The modeled velocity is the "fully coupled" velocity, as it is an integration result with ice geometry, temperature, and surface elevation all allowed to change, under the reanalysis atmospheric conditions. As in the case of the general geographic patterns of large flow features [Fahnestock et al., 1993], both SEGMENT-ice and PISM (a model based on shallow ice approximation [see Bueler and Brown, 2009]) provide acceptable simulations. Compared with PISM, which simulates a very concentrated northeast Greenland ice stream (in Region II, defined in Figure 2); SEGMENT-ice's simulation of the northeast ice stream is broader than observed. For the western side of the central ridge, the SEGMENT-ice simulated geographical patterns of the large ice speed are closer to observed than PISM, which simulated two more concentrated ice streams that correspond to Jacobshavn Isbræ (the narrow convergent region along the $68^{\circ} \mathrm{N}$ parallel in Region I) and a region to the north (along $\sim 74^{\circ} \mathrm{N}$ ). Our flow magnitude is generally smaller than the observed and the PISM simulations, for the narrow troughs such as the Jacobshavn. The advantage of our parameterizations, such as the granular basal sliding, should be more salient at the southeast section of GrIS. Unfortunately, the observations in this area are too limited for validation.

[14] With these InSAR surface flow data, our surface velocities also can be verified on a region by region basis. For the peripheral outlet glaciers such as Jakobshavn Isbrae, Helheim, and Kangerdlugssuaq, flow speeds can double in several years. Comprehensive mapping indicated that discharge from Greenland increased by over 30\% from 1996 to 2005 , as many of the ice sheet's outlet glaciers south of $70^{\circ} \mathrm{N}$ sped up by $\sim 50-100 \%$ [Rignot and Kanagaratnam, 2006]. Thus the very large flow speeds at several marginal locations may not be directly comparable with the modeled speeds, which supposedly are the climatological values for at least several decades. Our emphasis is on areas above the $500 \mathrm{~m}$ elevation contour (roughly for flow magnitudes less than $500 \mathrm{~m} / \mathrm{y}$ ). In Figure 2, velocity components are compared for Region I (the drainage area contains Jakobshavn Isbrae), Region II (contains the fast glacier Kangerdlugssuaq), and Region III (contains the northeast ice stream).

[15] Region I is the source region for the mostly landterminating glaciers, as well as the fast-flowing, marineterminating outlets such as Jakobshavn Isbrae. The statistics provide an objective metric for the quality of the model simulations. The model tends to underestimate both horizontal velocity components. Because the degree of underestimation is about $7 \%$ for both components, the flow direction is accurately estimated. Few grid points have flow direction errors. A cautionary note is that the ice-flow velocity in the narrow, fast-moving outlets should not be compared with the model results because the flow speeds are 


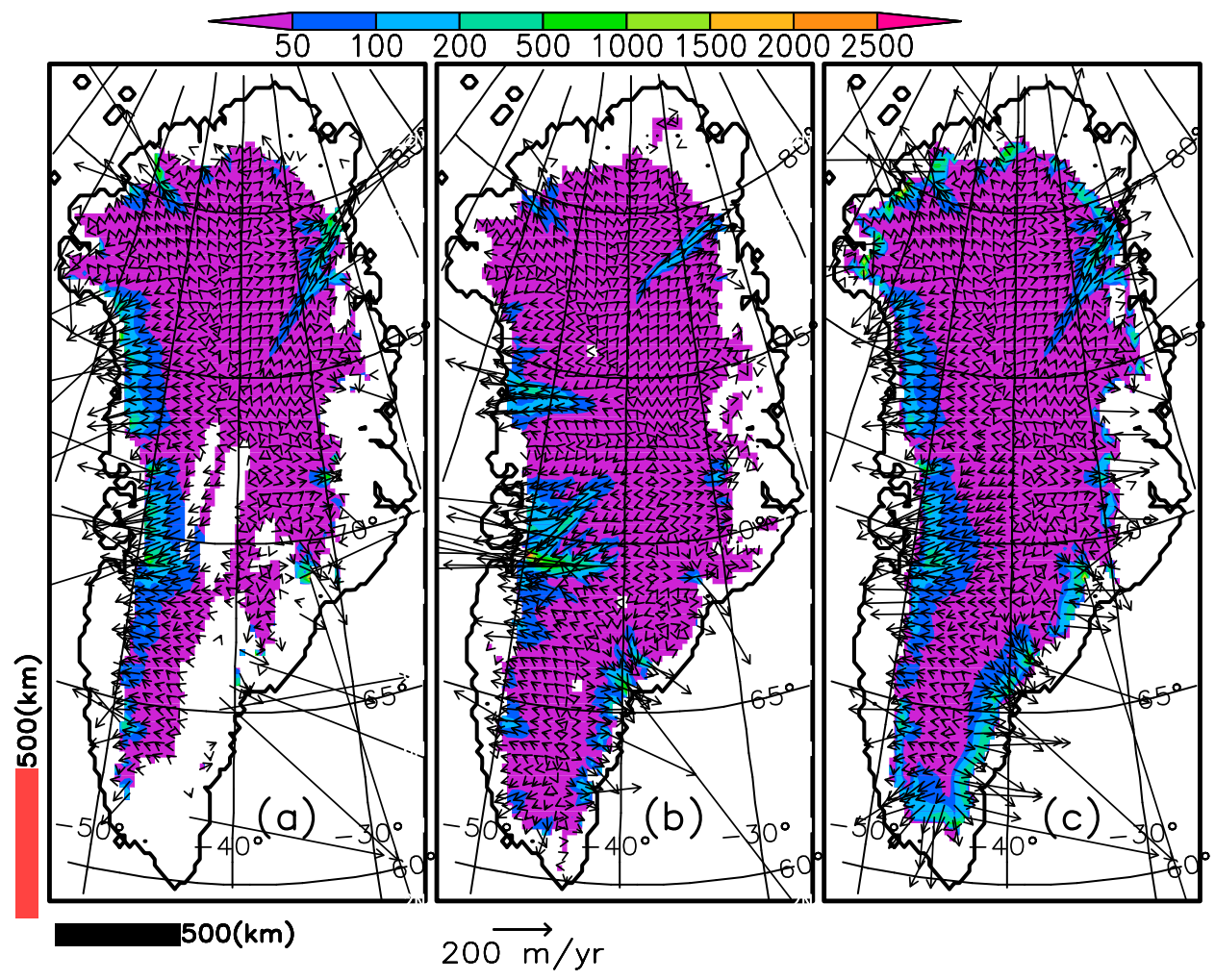

Figure 1. (a) The surface velocity fields at present as measured by InSAR (http://websrv.cs.umt.edu/isis/ index.php/Present_Day_Greenland), simulated by (b) PISM and (c) SEGMENT-ice. Ice sectors are clearly identifiable from flow patterns. In plotting the vector field, the data have been thinned for clarity by displaying one in every eight data grids.

almost depth-independent, caused by the stress discontinuity not resolvable at a $5 \mathrm{~km}$ spatial resolution. In Region II, the horizontal velocity components have linear regression coefficients (slopes of scatterplots of SEGMENT-ice modeled versus InSAR observations) of 0.75 and 0.8 . Comparatively, Region I has only $\sim 0.43$ linear regression coefficients. Region III has higher linear regression coefficients ( $\sim 0.82$ for both velocity components). That Region III has the best model-observation correlation may arise from the fact that observational data for this region is of the highest quality, as a result of the high degree of swath overlap as orbits converge near the pole. PISM simulated ice stream locations do not agree well with the observed (e.g., the northeast ice stream located too to the north). The linear regression coefficients for Region II are only around 0.23. For Region I, because southerly flow is not represented well in PISM, the north-south velocity component correlation with InSAR is only 0.2 .

[16] Our modeled speeds for the southeast corner are as large as $2000 \mathrm{~m} / \mathrm{y}$ (the arrows in Figure 1c), significantly larger than PISM. Because this region has larger accumulation rates than in the north GrIS [Ohmura and Reeh, 1991; Ettema et al., 2009], its mass balance is a highly dynamic balance between large flow divergence and higher accumulation rate. This region of high mass turnover may be more sensitive to climate change. Unfortunately, InSAR coverage is poor for this region. With few exceptions, notably the northeast stream and the marginal areas, most areas have relatively slow speeds. The model speeds, however, are slightly higher $(2-5 \%)$ than observations for most low flow speed regions. Because the ice is thick and nonfractured here, a slight underestimation of the flow speed means nonnegligible underestimation to the overall flow divergence.

[17] In addition to the horizontal resolution limitations $(5 \mathrm{~km})$, the model also cannot reproduce the flow of the narrow outlet glaciers because the forcing is primarily the atmospheric forcing of the ice sheet. Ocean water temperatures that induce disintegration of floating ice tongues of outlet glaciers by bottom melting are not considered. This mechanism has been shown to be a cause of the very recent acceleration of the outlet glaciers.

[18] Figure 3 shows the horizontal velocity components of the surface ice layer. Drainage basins [Zwally and Giovinetto, 2001] are clearly identifiable. Areas with significant vertical velocity components $(>10 \mathrm{~m} / \mathrm{y})$ collocate with regions with basal granular material (hatched area in Figure 3c). Because granular viscosity is less than the ice viscosity of the GrIS region, existence of a dilatant granular layer enhances the overlain ice flow speed. If the granular materials are geographically uniformly distributed, the effects on flow divergence are minimal except for the Summit and near the grounding line. However, for real topography and thickness profiles, existence of a dilatant granular layer can significantly affect the flow divergence/convergence field, and hence the mass balance, through the following positive feedback (using fast glacier as an example). Increased basal sliding significantly reduces resistive force and may trigger 

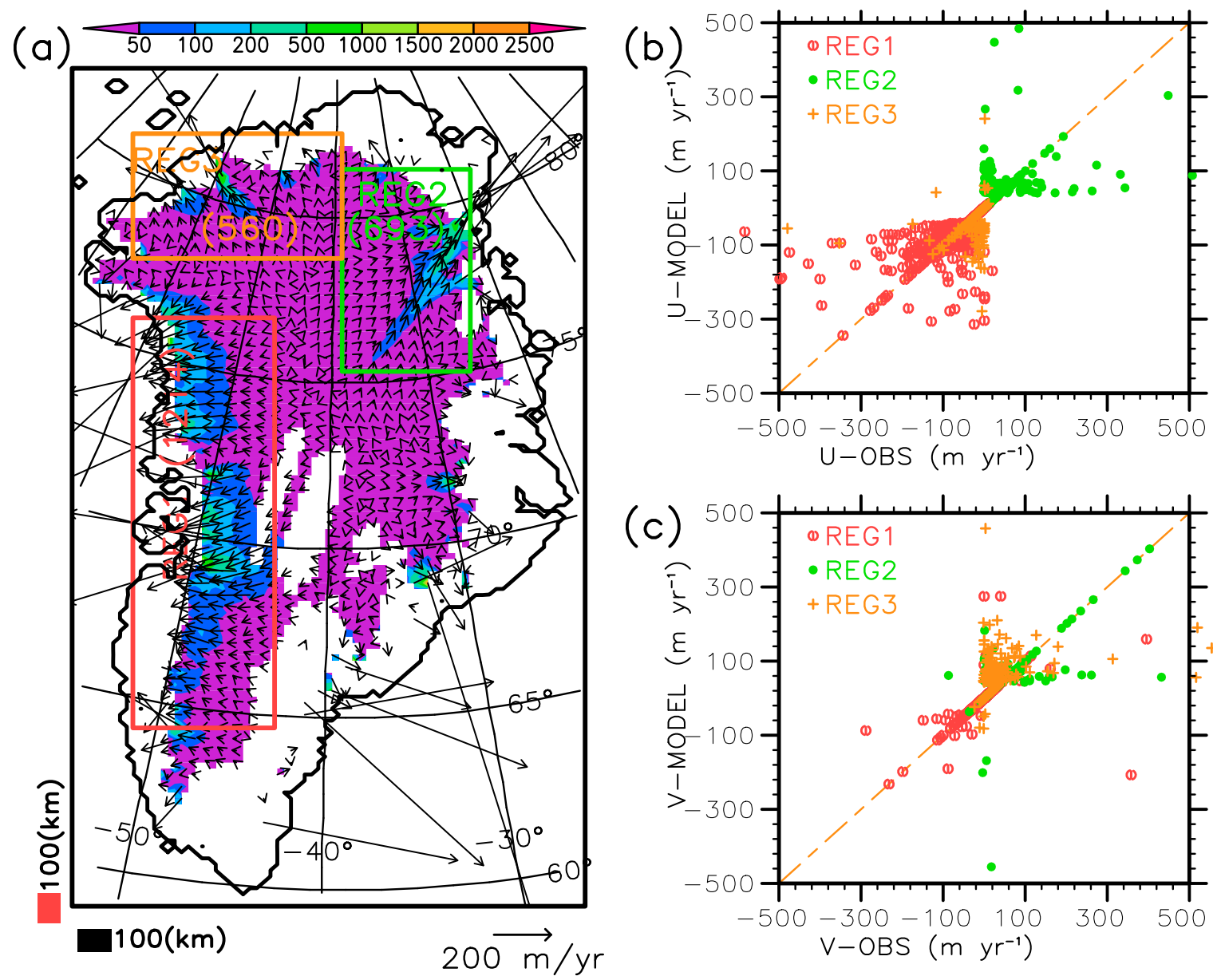

Figure 2. Region-by-region comparisons between SEGMENT-ice and InSAR observations of the present surface velocity fields. (a) The observed velocity field is representative of the early 21 st century speeds. The SAR data were provided by the Canadian Space Agency and then processed by the NASA-funded Alaska SAR facility. These are surface parallel flow components. No true vertical velocities are shown because the inaccuracies caused by slope errors are too large. (b) A region-by region scatterplot of the $u$-component and (c) for the v-component.

an ice outspread, signifying a lowering of the mass toward lower elevation and a thinning of the upstream ice. The outspread ice is clearly out of balance even with the current climate, and this ice will melt quickly. The meltwater helps wash away part of the sediments, lowers the snout, and sends the ice-sediment interface slope farther away from the supercooling threshold [Alley et al., 2005]. This makes the basal drainage system more efficient and encourages further erosion and sediment production. Ice outspread also helps remove the silt because the more concentrated drainage flow from encapsulated subglacial streams increases bed load transport capacity. Compared with the initial geometry, the snout is now thinner. In a warming climate, this positive feedback loop continues and signifies an enhanced mass loss rate.

[19] The monthly integration time step allows estimation of the summer maximum surface melt extent (SME), a sensitive warming index and useful representation of the ablation zone temporal variability. Microwave measurements yield good estimations of the GrIS surface melt extent and duration because brightness temperature and the normalized microwave-radar backscatter coefficient (cross-section) both are sensitive to liquid water present in snow [Ashcraft and Long, 2006]. The seasonal surface melt extent on the GrIS has been observed by satellites since 1979 and shows an increasing trend (see Figures $2 \mathrm{a}$ and $2 \mathrm{~b}$ and chapter 6 in the work of $A C I A$ [2005]). Warming is central to the expansion of SME. Contrary to the opinion that melting is perfectly related to air temperature, field experiments (L.Thompson, personal communication, 2007) demonstrate that melting occurs even when air temperatures are well below freezing point; it is the net energy input that matters [Van den Broeke et al., 2008]. This is further supported by a recent study by Fausto et al. [2009]. They used a positive degree day method and successfully simulated the surface melt extent of the same observational data set. They found the definition of remote sensed melt area includes both the melt snow zone and runoff zone instead of only the latter. The vertically stretched grid stencil, by making the top layer thin enough to be sensitive to atmospheric forcing on monthly variations, facilitates identification of surface melt area. If the land surface model indicates that the top ice/snow layer is generating water, a grid point is in a melt state. 


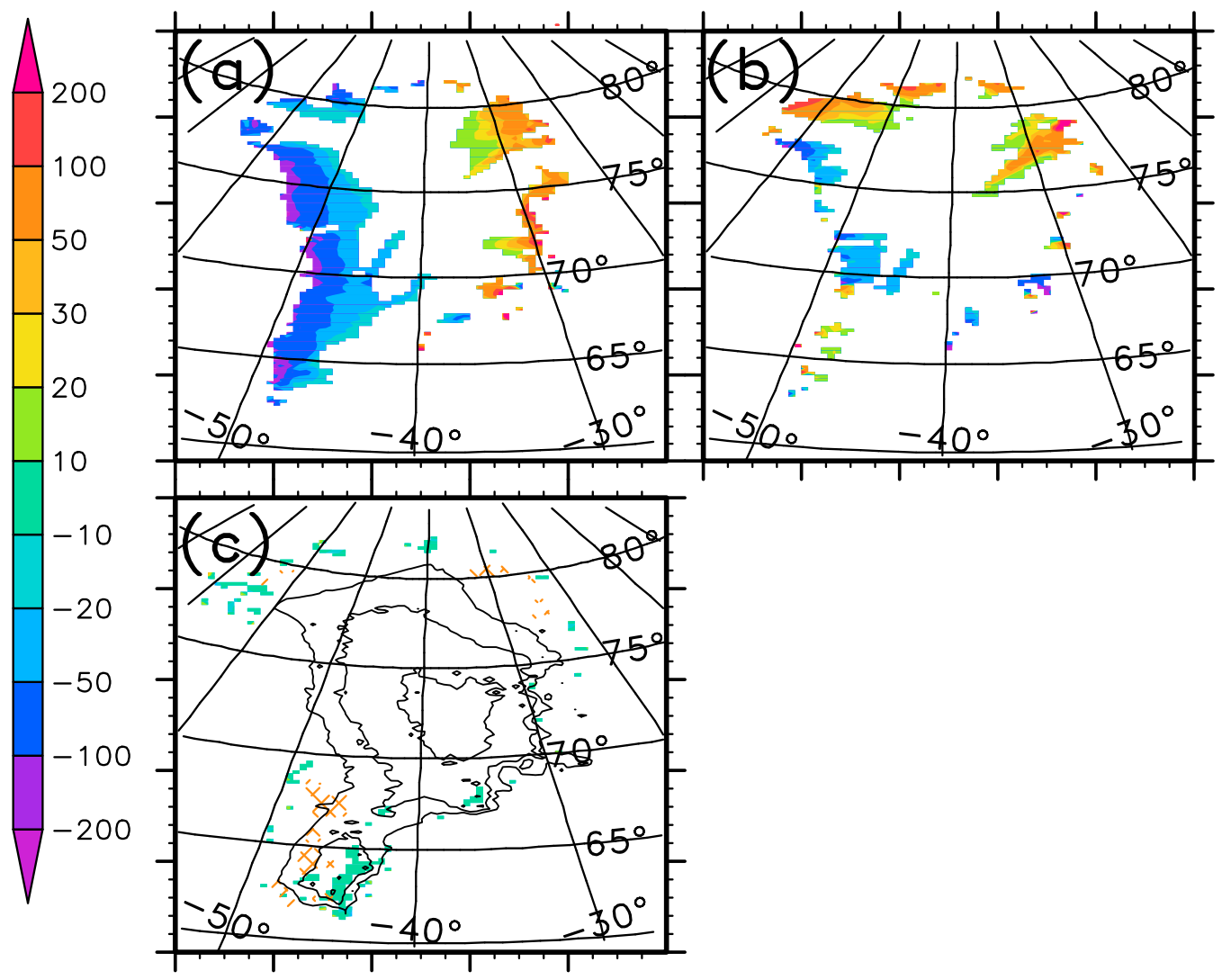

Figure 3. SEGMENT-ice simulated of the present (1980-1999) surface flow fields (m/y): (a) $u$-component (west-east), (b) $v$-component (south-north), and (c) the w-component (vertically upward) of the full vector flow field. It is clear that the vertical flow is significant at the peripheral (marginal) areas, collocated with areas with granular basal sliding (hatched areas in Figure 3c). White spots in Figures 3a and 3b have speeds less than $10 \mathrm{~m} / \mathrm{y}$. The shallow ice approximation may be a good approximation for the inland areas of the GrIS. However, for the margin areas, a full Navier-Stokes treatment is necessary.

[20] The remote sensing observed SME is processed from the National Snow and Ice Data Center (NSIDC) archive of brightness temperature in a $25 \times 25 \mathrm{~km}$ grid on a polar stereographic projection [Maslanik and Stroeve, 2007]. At this resolution, the total area for the ice sheet is $\sim 1.76 \times$ $10^{6} \mathrm{~km}^{2}$, close to what our model produces. Integration over pixels that have at least 1 day with melt yields the total annual melt area. Our model views this phenomenon on a monthly time scale. For comparison, we take the maximum extent of each year and generate an annual time series.

[21] First, the model is driven by CCSM-provided preindustrial (100-year-long monthly meteorology) and 20C3M atmospheric conditions. The CCSM data then is replaced with the NCEP/NCAR reanalysis of precipitation, temperature, and radiative fluxes for the segment covering year 1948 to present. Using these above criteria, the modeled SME from year 1979 to 2006 (Figure 4) compares well with the cross-polarized gradient ratio method (XPGR) [Abdalati and Steffen, 1997] observed melt area in terms of annual variabilities. For example, the relative maxima in years 1998-1999, 2002, 2005, and 2007 are satisfactorily simulated. A high correlation coefficient (after removing linear trends from both time series) of 0.88 is found between this time series and the observed 1979-2007 melt area. In the 30 -year model simulation series, the surface melt exhibited large interannual and decadal variability, with years 2002 , 2005, and 2007 being three known significant recent melt episodes.

[22] The total melt area is, however, a highly averaged metric. To further investigate the model fidelity, the geographic distribution of the surface melt area is examined (figure not shown). The modeled SMEs at years 1992 and 2002 both compare well with the observed, which is unlikely to be a coincidence. During this decade, the peripheral and the southern part of the SME expanded significantly, especially the western side facing Baffin Bay, corresponding closely to the atmospheric forcing during this period. Consequently, the area of maximum SME increased from $\sim 0.34$ million $\mathrm{km}^{2}$ in 1992 to $\sim 0.58$ million $\mathrm{km}^{2}$ in 2002 .

[23] Time-variable gravity measurements from the Gravity Recovery and Climate Experiment (GRACE) satellite mission can be used to estimate ice mass changes over Greenland [Chen et al., 2006; Wouters et al., 2008]. Presently, there are 598 maps, covering the period April 2002 to September 2008, of gravity anomaly from GRACE project. The GRACE measured total mass change is compared with the model simulation driven by NCEP/NCAR provided meteorological parameters [Ren et al., 2010, Figure 6]. The model simulation shows larger seasonal variability than GRACE. Both show significant melting in the years 2002 


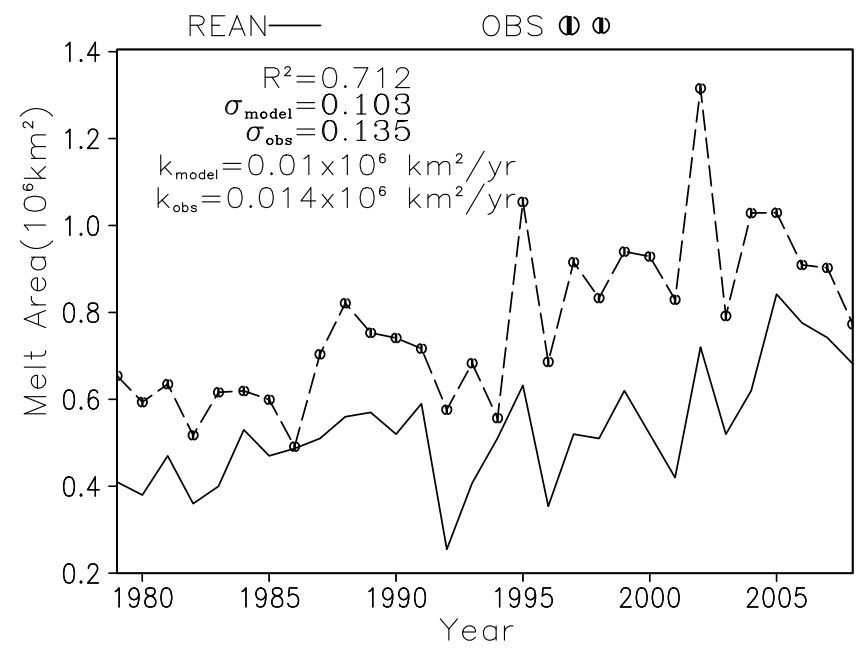

Figure 4. Observed (circular-with-vertical-bar markers) and simulated (solid line) maximum melt surface area extent. Observations are adapted from the annual melt extend data (NSIDC, http://nsidc.org/). Measurements are derived from passive microwave satellite brightness temperature characteristics using the cross-polarized gradient ratio (XPGR) of Abdalati and Steffen [1997]. The modelpredicted extent during the years 1979 and 2008 are driven by NCEP/NCAR reanalysis atmospheric conditions.

and 2007, in accord with recent observational studies [e.g., Mote, 2007]. The model also indicates 2005 is a year with significant mass loss. The GRACE curve shows a spike in the summer ablation period of 2004 that is not supported by physical mechanisms. The ice data likely is aliased during this period. If the aliased signal is corrected, the model simulation and GRACE measurements agree well in the annual changes in GrIS total mass (i.e., year 2005 is also a year of large mass loss) for the following years. The modeled spike in early 2006 is also confirmed by GrIS mass balance survey (S. Nghiem, personal communication, 2009), which shows a large accumulation during 2005 winter to 2006 spring accumulation season. The GRACE has a smoother signal than our model, as is expected. GRACE observations and SEGMENT-ice simulations have similar mass loss rates: about -147 and $-160 \mathrm{~km}^{3} / \mathrm{y}$, respectively, over 2002-2008.

[24] The large area of mass loss over the southeast Greenland ice sheet shown by Wouters et al. [2008] is not precisely reproduced by the model simulation. However, the model does indicate that the southeast GrIS has a sophisticated mass balance structure and is in a delicate balance between large accumulation and large ablation. Owing to the coarse GRACE spatial resolution, it cannot identify specific details over the southeast region. The SEGMENTice simulated western mass loss of the GrIS agrees more closely with Wouters et al. [2008], which used 5 years of GRACE data, than with Chen et al. [2006], which used only 3 years of GRACE measurements. For example, the northwest mass loss peak in the work of Chen et al. [2006] is absent in Figure 1 of Wouters et al. [2008]. According to Wouters et al. [2008], their improvements over Chen et al. [2006] arise from their technique for improving the hori- zontal spatial resolution. A linear fit to the trend provides a mass change rate map from the 598 snapshots. The GRACE measurements provide a smooth mass loss centered on the southeast, up to $-8 \mathrm{~cm} / \mathrm{y}$ at the intersection of $68^{\circ} \mathrm{N}$ and $39^{\circ} \mathrm{W}$. Earlier data covering GRACE measurements up to November 2005 indicated a northern mass loss region (point B, Figure 2 of Chen et al. [2006]). This signal disappeared when new data is included ( $\mathrm{J}$. Chen, personal communication, 2009), confirming that the 2004 spike in the total mass loss curve is indeed a spurious signal.

[25] Ice temperature is critical in quantifying the total mass loss and the relative contribution from surface runoff and ice flow divergence. Having the recent GrIS properties validated by remote sensing data, an investigation is made of the trend of surface ice temperature over this century under global warming conditions. The nonmitigated, weak emission scenario B1 [Nakicenovic and Swart, 2000] is used. Figure 5a is the result from NCAR-CCSM3 B1 provided meteorological forcing. Counterintuitively, there are cooling areas at lower elevations, especially to the northern section. Further analysis of the respective contribution from different terms (in the thermal equation) indicates this is due to horizontal advection of central (inland) part colder ice. Because the ice temperature is higher at this lower elevation area, the ice flow is large and the horizontal advection dominates other heating factors (e.g., sensible heat flux and precipitation). In the vast central section, horizontal advection (a cooling effect) is relatively small and warming from sensible heat flux dominates. In between, there is a ring of the most prominent warming; it corresponds well with the areas with strong precipitation input. There are $\sim 1.4$ million $\mathrm{km}^{2}$ of surface areas experiencing apparent warming $\left(>0.5^{\circ} \mathrm{C}\right.$ by 2100 ), but only $\sim 10 \%$ (mostly low lying marginal areas) of the surface area cools. Because the limited cooling areas are distributed at relatively warmer regions at lower elevation, it does not greatly affect surface runoff, as it melts during the summer months. The extensive warming area inland, however, imposes a divergent ice flow field on the original, near balanced one. Using MIROC3.2hires output as forcing gives qualitatively the same results.

[26] The vertical ice temperature field shows that warming reaches deeper than $100 \mathrm{~m}$ by the end of the 21 st century for most areas. Even for the summit (Figure 5b), the temperature increase is steady. In Figure 5b, the final 10 years of annual mean temperature are plotted for the upper $20 \mathrm{~m}$. There is more than a $0.5^{\circ} \mathrm{C}$ increase even under the weak B1 emission scenario assumption. In addition to vertical advection and increases in sensible and latent heat fluxes, strain heating is a mechanism that works faster and explains most of the warming deeper than $100 \mathrm{~m}$. Although there is clear annual variability, it is unlikely for the ice temperature cools back to the 1993 level.

[27] The atmospheric forcing of CCSM3 is adopted, respectively under the three nonmitigated IPCC Special Report on Emission Scenarios (SRES): B1 (low), A1B (medium), and A2 (high rate of emission) emission scenarios. Total ice volume is a highly aggregated metric, and the trend of the curve is interplay of quite a few factors. Since the inland part of GrIS is still significantly cold, the feedback from increasing precipitation is significant so that the estimations of the GrIS total mass loss are less sensitive to scenario 
assumptions before 2030, although the atmospheric forcing starts to diverge from year 2000. Afterward, as atmospheric forcing further diverges, the differences become apparent. Further examination of the different terms in the total mass balance indicates that the effect of higher precipitation amount from strong scenario is eventually dominated by the increased ice flow divergence and increased meltwater runoff. After 2060, there is an acceleration trend for mass loss rate. This primarily is because the basal sliding mech-

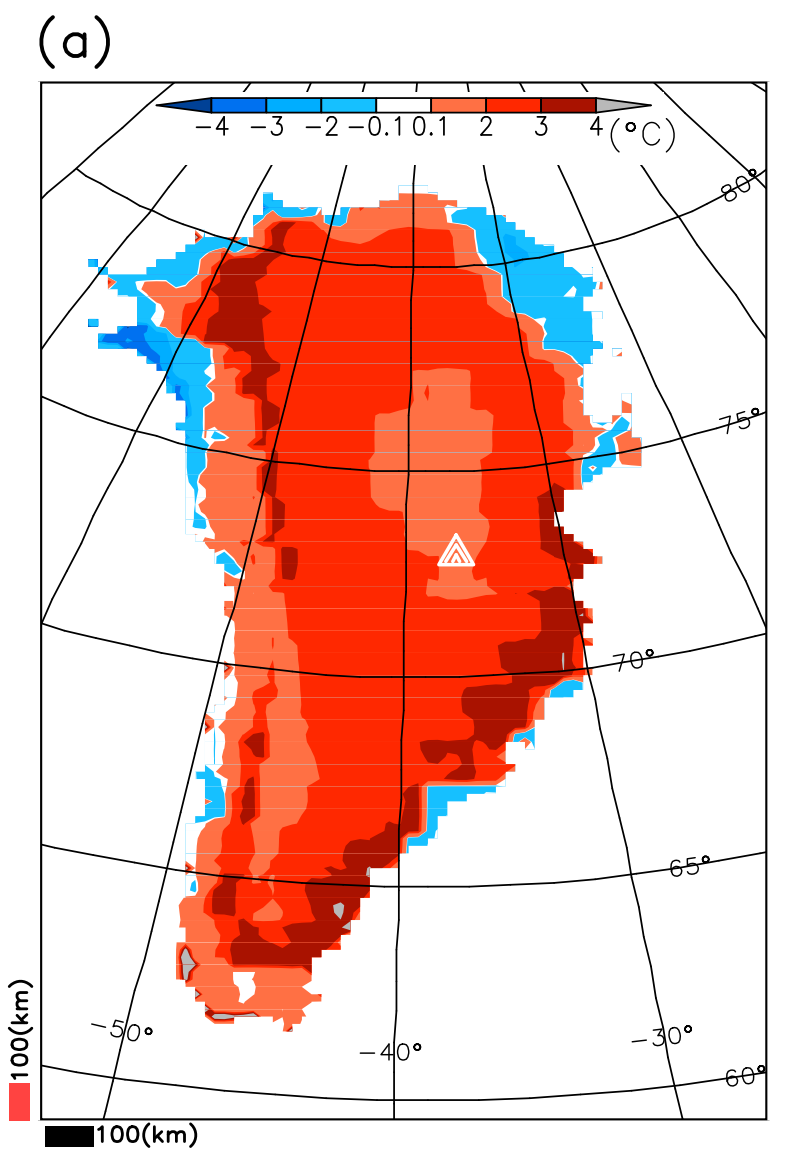

(b)

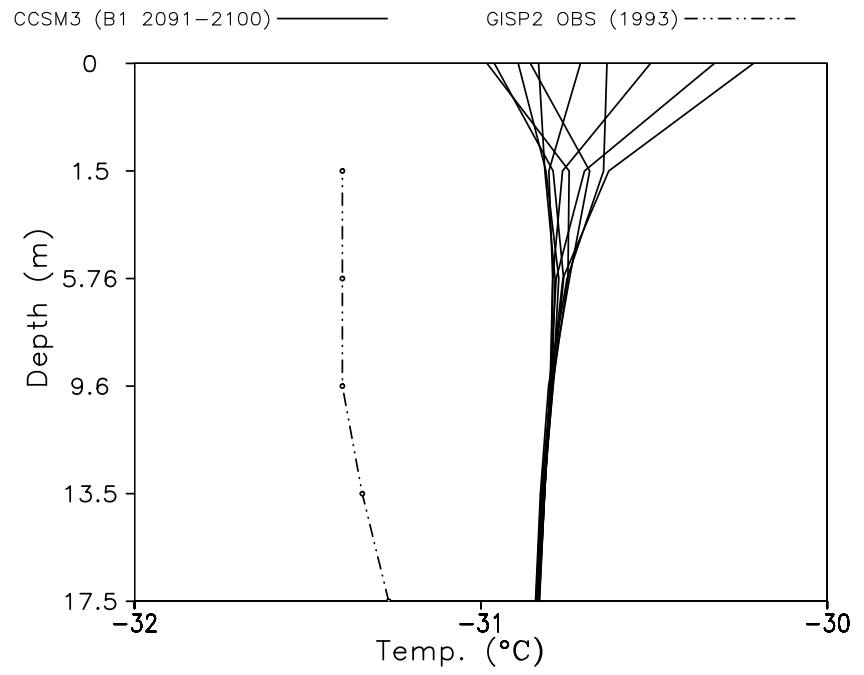

anism becomes significant, especially beneath the southern tip and the northeast ice stream, and signifies a quicker mass shed, in accordance with Alley et al. [2005]. By the end of the 21 st century, if the moderate A1B scenario is realized, the total mass loss rate should reach $\sim 220 \mathrm{~km}^{3} / \mathrm{y}$.

[28] As the climate warms, the increases of temperature and precipitation both scale nonlinearly with the strength of the emission scenarios. Without sophisticated numerical modeling, it is very difficult to ascertain even the direction of total mass change and even more difficult to quantify the interscenario differences. With SEGMENT-ice, it is clear that the temperature signal dominates. Both surface runoff and ice divergence increase as air temperature warms up. Examining the relative contribution from surface melt and from ice flow divergence indicates that the fraction from the latter increases during the transient climate change period. Hence it is likely that the total glaciated area does not vary much but that the mass loss accelerates as climate warms. At present the surface melt and ice flow divergence are almost equally important [Rignot and Kanagaratnam, 2006]. Current partitioning is symptomatic of ongoing near-surface warming. By the end of this century, under the moderate A1B scenario the share of ice divergence will be about $60 \%$, thereby outweighing the contributions from the various surface processes.

\section{Conclusions}

[29] A thermomechanically coupled, diagnostic Stokes model was used by Zwinger et al. [2007], while models presented by Pattyn et al. [2008] are prognostic but are isothermal and applied to glacier-sized problems. In this study a new, prognostic thermomechanically coupled, full Navier-Stokes ice sheet model, with granular basal sliding, is applied to the entire GrIS. This ice model is referred to as SEGMENT-ice and in Appendix A there is a full description of the governing dynamic and thermodynamic equations, numerical solver techniques, and the boundary conditions. The parameterizations for granular material, a ubiquitous presence for glaciated landscape, also are detailed. The procedure is outlined for obtaining a steady flow field that is in agreement with the present temperature

Figure 5. Surface ice temperature changes 2000-2010 simulated by SEGMENT-ice: (a) driven by the NCARCCSM3 (B1) scenario for meteorological forcing. (b) The top $17.5 \mathrm{~m}$ temperature profile around summit (white triangle) is zoomed for 2091-2100. The upper $20 \mathrm{~m}$ ice temperature increased $\sim 0.5^{\circ} \mathrm{C}$ under this weak emission scenario compared with 1993 observations (dot-dot-dashed line). In Figure 5a cooling areas at lower elevations exist, especially in the north, likely due to horizontal advection of inland, colder ice. Because ice temperatures are higher at these lower elevations, the ice flow is large and horizontal advection dominates other heating (e.g., sensible heat flux and precipitation). In the vast central GrIS, horizontal advection (a cooling effect) is relatively small and sensible heat flux warming dominates. In between is a ring with greatest warming, corresponding with strong precipitation input, which usually heats the ice. 
regime and ice geometry. This is a prerequisite for climate sensitivity experiments of the ice sheet states to meteorological forcing. The modeling system is validated using the remote sensing measurements of the GrIS.

[30] Several recent surveys, using airborne and spaceborne remote sensing technique, indicate dramatic changes in GrIS surface melt, surface flow field and total mass loss during the past decade [Rignot and Kanagaratnam, 2006; Velicogna and Wahr, 2006; Joughin et al., 2008]. Because meltwater is an important source for sea level rise, it is desirable to predict the future states of the GrIS. In this study, the model is driven using two CGCM model outputs and NCEP/NCAR reanalysis atmospheric parameters. The reanalysis-driven experiments compare favorably with the mass loss rates derived from GRACE, and the SSM/I observed surface melt extent area agrees in terms of geographical distribution and annual variability of the total amount. The model also satisfactorily simulates the laser observed present-day surface flow field. Simultaneously satisfying the three metrics gives confidence that the model can predict future total mass loss rate and hence the sea level rise contribution of the GrIS, in future meteorological forcing conditions. A projection of the GrIS temperature regime by the end of this century indicates that global warming will superimpose a divergent flow field enhancing total mass loss.

[31] Ice sheet models conventionally assume local force balance, under the assumption that with near-steady state conditions, the climatically controlled surface balance (snowfall minus melt) controls the geometry of an ice mass. Changes in thickness are forced primarily by changes in surface mass balance. In contrast, the results from SEGMENT-ice suggest that changes in ice velocity might also be forced by changes in subglacial mechanics, in addition to upper boundary thermal regime changes. This conclusion is especially relevant for a future warming climate. Many of the observations described above were made after the IPCC finished its Four Assessment Report (AR4). The observed changes were rapid, large and well beyond those predicted by the shallow ice models used to make the AR4 sea level assessments. The observed changes revealed shortcomings of present ice dynamics models which use incomplete Navier-Stokes equations and oversimplify the physical parameterizations. IPCC AR4 concluded that changes in ice dynamics may cause a large contribution to sea level for which upper bound cannot be found from present knowledge (Chapter, IPCC 2007). The present study helps fill a knowledge gap in ice sheet research, by increasing our understanding of the Greenland ice sheet response to climate change.

[32] The most significant changes in the flow pattern of the GrIS are at the ice sheet margins, where fast-flowing ice streams discharge large amounts of ice into the ocean. For example, Rignot and Kanagaratnam [2006] indicate that Jacobshavn-Isbræ, with a width of only $5 \mathrm{~km}$, contributes up to $7-10 \%$ to the total ice discharge from the GrIS. Because of their comparably large aspect ratios, ice streams and the surrounding transition zones are the areas where a full Navier-Stokes model is expected to be superior to shallow models but only if the mesh size is small enough. The current grid size of $5 \mathrm{~km}$ is not able to capture the geometry of these ice streams adequately. Future efforts will use the recently available $1 \mathrm{~km}$ ice digital elevation and thickness data for very high-resolution regional simulations of GrIS behavior.

\section{Appendix A: The SEGMENT-Ice Model}

[33] The governing dynamic equations of SEGMENT-ice are

$$
\begin{aligned}
& \frac{\partial R_{x x}}{\partial x}+\frac{\partial R_{x y}}{\partial y}+\frac{\partial R_{x z}}{\partial z}-\rho g \frac{\partial h}{\partial x}=\rho\left(\frac{\partial u}{\partial t}+u \frac{\partial u}{\partial x}+v \frac{\partial u}{\partial y}+w \frac{\partial u}{\partial z}\right) \\
& \frac{\partial R_{x y}}{\partial x}+\frac{\partial R_{y y}}{\partial y}+\frac{\partial R_{z y}}{\partial z}-\rho g \frac{\partial h}{\partial y}=\rho\left(\frac{\partial v}{\partial t}+u \frac{\partial v}{\partial x}+v \frac{\partial v}{\partial y}+w \frac{\partial v}{\partial z}\right) \\
& \frac{\partial R_{x z}}{\partial x}+\frac{\partial R_{y z}}{\partial y}+\frac{\partial R_{z z}}{\partial z}=\rho\left(\frac{\partial w}{\partial t}+u \frac{\partial w}{\partial x}+v \frac{\partial w}{\partial y}+w \frac{\partial w}{\partial z}\right)
\end{aligned}
$$

where $t$ is time; $x, y$, and $z$ are coordinates pointing east, north, and upward; $u, v$, and $w$ are the components of the velocity vector $V=(u, v, w)^{T}$; h is the elevation of the free surface; $\rho$ is ice density; and $\mathrm{g}$ is gravity acceleration. Following Van der Veen and Whillans [1989], resistive stress is defined as $R_{i j}=\sigma_{i j}-\delta_{i j} L$, with $\sigma_{i j}$ being the full stress, $L=-\rho g(h-z)$ the lithostatic stress, and $\delta$ the Kronecker operator. Because the deviatoric stress tensor is related to the deviatoric part of the strain rate tensor by the viscosity $\eta$, we have the following constitutive relationship

$$
\left\{\begin{array}{l}
R_{i j}=\eta \times \dot{\varepsilon_{i j}} \text { for } i \neq j \\
R_{i i}=\eta \times\left(2 \dot{\varepsilon_{i i}}+\dot{\varepsilon_{j j}}\right)+R_{z z} \text { for } i \neq j=x, y
\end{array}\right.
$$

Here the strain rate tensor is defined as

$$
\dot{\varepsilon_{i j}}=\frac{1}{2}\left(\frac{\partial u_{i}}{\partial x_{j}}+\frac{\partial u_{j}}{\partial x_{i}}\right), i, j=x, y, z .
$$

[34] We assume the ice is incompressible

$$
\nabla \bullet \stackrel{D}{V}=\frac{\partial u}{\partial x}+\frac{\partial v}{\partial y}+\frac{\partial w}{\partial z}=0
$$

The isotropic pressure $R_{z z}$ is the integrated effect of (overlain) ice acceleration/deacceleration and is diagnosed at each time step. Equations (A1) through (A4), by applying the constitutive law and the mass conservation relationship, reduce the unknowns to the three velocity components $(u, v$, and $w$ ) and make a full closure for $u, v$, and $w$. On the basis of conservation of mass, momentum, and energy, originally nonglaciated grids can be glaciated and conversely.

[35] Parameterization of viscosity is critical for the numerical model. As a non-Newtonian fluid, polycrystalline ice has a shear-thinning rheology in which the strain rate is proportional to the applied deviatoric stress raised to an exponent [Glen, 1955]. This proportionality is temperature and second invariant of the strain rate tensor dependent 


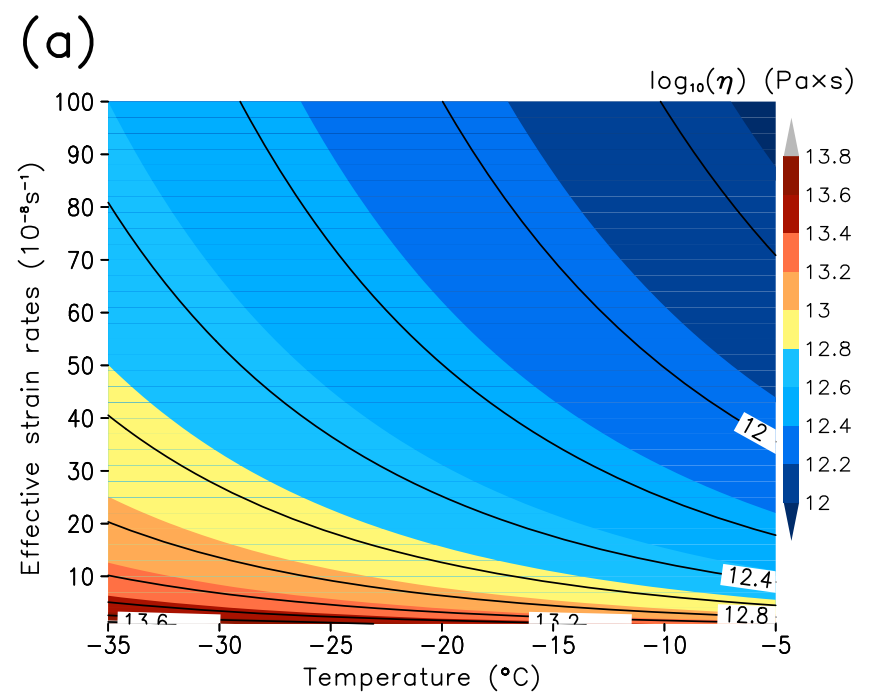

(b)

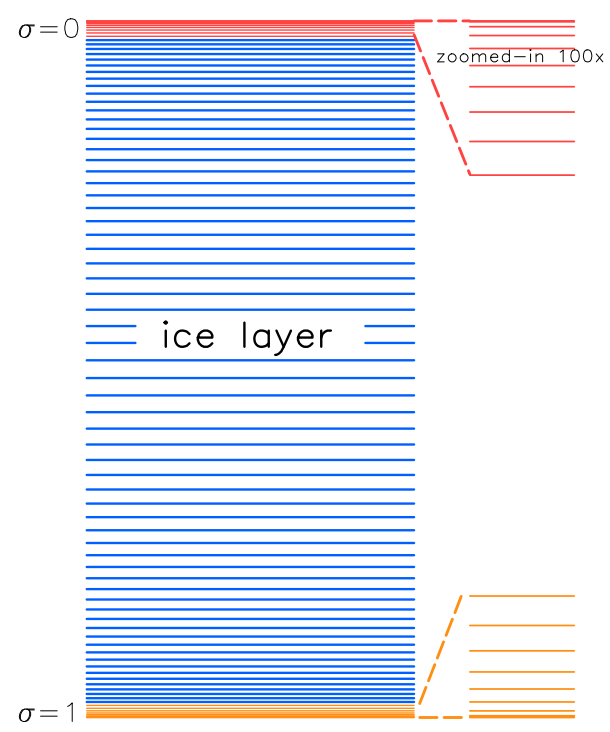

Figure A1. (a) The ice viscosity $(\eta)$ parameterized in SEGMENT-ice. Shaded contours are from the Glen law parameterization $(\mathrm{n}=3)$. The fabrication enhanced viscosity [Wang and Warner, 1999] is shown as contour lines. It is apparent that both strain states and temperature need to be accurately represented. (b) The SEGMENT-ice uses a stretched vertical grid stencil. The thickness of the very first layer ( $\sigma=0$ in the terrain-following coordinate system) is $1.5 \times 10^{-4}$ times the local ice thickness.

[Goldsby and Kohlstedt, 2001; Paterson, 1994; Hooke, 1981].

$$
\eta=A^{-\frac{1}{n}}\left(\dot{\varepsilon}_{e}\right)^{\frac{1}{n}-1} \dot{\varepsilon}_{i j}
$$

[36] Here, the effective strain rate, or the second invariant of the strain rate, is defined as $\dot{\varepsilon_{e}}=\sqrt{\frac{1}{2} \operatorname{tr}(\dot{\varepsilon})^{2}}$. In SEGMENTice, the default value for $n$ is 3 (traditional Glen's flow law). The flow rate factor, $\mathrm{A}(\mathrm{T})$, is derived from the Arrhenius law [Paterson, 1994; Hooke, 1981]. In SEGMENT-ice,
$A=A_{0} e^{\left(-\frac{Q}{R T}+\frac{3 C}{\left(T_{0}-T\right)^{k}}\right)}$, with $\mathrm{A}_{0}=9.3 \times 10^{-2} \mathrm{~Pa}^{-3} \mathrm{y}^{-1}, \mathrm{Q}=$ $78800 \mathrm{~J} / \mathrm{mol}, \mathrm{R}$ is gas constant $(8.31 \mathrm{~J} / \mathrm{mol} / \mathrm{K})$, experimental constants $k=1.17, \mathrm{C}=0.166 \mathrm{~K}^{k}$, and $T_{0}=273.39 \mathrm{~K}$. For the GrIS ice domain, this parameterization gives a viscosity range of $4 \times 10^{13}$ to $1.1 \times 10^{15} \mathrm{~Pa} \cdot \mathrm{s}$ (shading in Figure A1a). We further implement the viscosity enhancement by fabricating (contour lines in Figure A1a) [Wang and Warner, 1999]. Like most current ice dynamic models, the model framework supports Glen [1955], Goldsby and Kohlstedt [2001], and Durham et al.'s [1992] flow laws.

[37] The movement of glacial ice is achieved by a combination of viscoplastic flow, sliding, and the deformation of underlying basal sediments. Pressure-melted water plays an important role in each of these processes. Weertman [1957, 1983] showed how the rate of ice sliding at the local pressure melting temperature (PMP) depends on scales of roughness elements on the glacier bed. However, the original form of Weertman's law does not fit into the framework of field dimension sliding [Hooke and Iverson, 1985], nor does it treat the frictional stresses exerted by entrained sediment particles, which have been identified as important contributors to the overall shear stress at the bed [MacAyeal, 1992; Hooke and Iverson, 1985]. The liquid-like layer separating the ice from the bedrock exists even for glaciers far below the bulk PMP at their beds [Gilpin, 1979]. This concept has been adopted by modellers and has been observed in the field [Shreve, 1984; Hallet, 1996]. The "grade-glacier" theory [Alley, 1993] generalizes silt production and transportation as an integrated component of the ice erosion on glacier bed. It shows that climate fluctuations, by modifying ice surface slope, can affect sediment transport and erosion patterns. This theory directly motivated the present research because the established warming climate may flatten the marginal area of the fast glaciers surrounding the GrIS and therefore encourage the deposition of granular sediments.

[38] Bueler and Brown [2009, and references therein], Engelhardt and Kamb [1998], and Greve and Blatter [2009] all pointed out the importance of basal sliding mechanism in ice sheet dynamics. A Weertman-type [Weertman, 1983] sliding law, with overburden pressure corrected for the subglacial water buoyancy, appears well-suited for describing large-scale flow features (see the detailed overview by Bindschadler [1983]). We follow Greve and Otsu's [2007] treatment of basal sliding coefficient $C_{b}=v_{b} / F\left(T_{p}, \tau, P\right)$. Here $v_{\mathrm{b}}$ is basal-sliding velocity and $\mathrm{F}$ is a function of ice temperature relative to pressure melting $\left(T_{\mathrm{p}}\right)$, overburden pressure $(P)$, and the basal shear traction in the bed plane $(\tau)$. The crevasse distribution [Zwally et al., 2002] may signify an important mechanism for surface meltwater drainage. Owing to a lack of survey data and large uncertainties in their distribution characteristics, it is difficult to directly parameterize effects of crevasses on basal sliding. Therefore we follow an empirical approach, which uses a surface meltwater coefficient, $\gamma$, usually between 0 to $6 \mathrm{y} / \mathrm{m}$, to enhance the basal sliding coefficient $C_{b}$, using the linear multiplier $(1+\gamma m)$, with $m$ being melt rate. The very existence of crevasses is a strong indication of uneven basal erosion, which produces granular material. It is unlikely that dry granular material lies under the ice sheet, so the activation of the granular sliding scheme is contingent upon the Weertman sliding. 
[39] Unlike ice, the viscosity of granular material depends also on the isotropic stress. For this granular sublayer, a newly proposed rheology [Jop et al., 2006] is applied, namely,

$$
\nu=\left(\mu_{0}+\frac{\mu_{1}-\mu_{0}}{I_{0} / I+1}\right) \frac{S}{\left|\dot{\varepsilon_{e}}\right|}
$$

where $\nu$ is granular viscosity, $S=\left(R_{k k}-\rho g(h-z)\right) / 3$ is the spherical part of the stress tensor $\sigma, \mu_{0}$ and $\mu_{1}$ are the limiting values for the friction coefficient $\mu, I_{0}$ is a constant depending on the local slope of the footing bed as well as the material properties, and $I$ is inertial number defined as $I=\left|\dot{\varepsilon}_{e}\right| \mathrm{d} /\left(S / \rho_{s}\right)^{0.5}$, where $\mathrm{d}$ is particle diameter and $\rho_{s}$ is the particle density. The granular layer thickness, basal material density, and the effective particle size are determined optimally using the datum period 1900-1950, when flow and mass are assumed in near balance. These parameters are thus spatially variable. For example, the effective grain size varies from $\sim 1 \mathrm{~mm}$ under the northeast ice stream to $>20 \mathrm{~mm}$ below the Jakobshaven ice stream. The thickness of granular material is proportional to the overlain ice thickness.

[40] For a specific location, there are two pathways contributing to its mass fluctuation: flow divergence/ convergence and boundary mass fluxes or surface mass balance $(S M)$. For the net mass balance of the ice sheet, runoff is arguably one of the most important quantities. We adapted a surface mass balance scheme from Simulator for Hydrology and Energy Exchange at the Land Surface (SHEELS) [Smith et al., 1993; Crosson et al., 2002]. SHEELS now is an integral component of SEGMENT-ice. In addition to the surface topography, SHEELS references Benson's [1962] zone mask. Given that all meltwater is not lost [Ohmura et al., 1996], all precipitation is assumed not to be net accumulation. We assume a total withholding of the mass for snow falling on the dry snow zone and percolation zone [Benson, 1962]. Melting water from the ablation zone is assumed to be lost in a manner analogous to water drainage from a porous soil layer. The analogy is between firm and sandy soil. This applies to other cases involving water redistribution among grids. The purpose of a carefully edited digital mask (referenced to the zones division in the work of Benson [1962]) is to investigate the refreezing of meltwater and hence to gain improved estimation of the net runoff. For possible rainfall in the ablation zone, an important mixing process is included (namely, the $Q_{m}$ term in equation (1) of Ren et al. [2007]) [Oerlemans, 2001, p. 48] because heat transferred to snow by rain during cooling to $0^{\circ} \mathrm{C}$ is significant [Peng et al., 2002].

[41] Flow divergence/convergence and surface mass balance cause the free surface elevation to fluctuate. The prognostic equation for $h(x, y)$ is

$$
\frac{\partial h}{\partial t}+\left.\left(\vec{V} \bullet \nabla_{H}\right)\right|_{t o p} h-\left.w\right|_{t o p}-S M=0
$$

[42] Where $X l_{\text {top }}$ indicates evaluated at the free surface elevation, $S M$ is the accumulation/ablation function. For ice with a marine termination or which lies above ground (reference a 3-D "phase mask" at each time integration), we apply zero-stress lateral boundary conditions for the momentum equation. The upper surface is always stress-free (i.e., $\left.R \bullet \vec{n}\right|_{t o p}=0$ ). This provides a reference value for diagnosing $R_{z z}$ in equation (A1c).
[43] The thermal equation is

$$
\begin{aligned}
& \rho c\left(\frac{\partial T}{\partial t}+(\stackrel{\otimes}{V} \times \nabla) T\right)-k \Delta T=\dot{Q} \\
& \dot{Q}= \begin{cases}\frac{2}{\eta} \times \sigma_{e f f}^{2} & \text { within solid ice } \\
G / H_{s f c} & \text { at the upper surface } \\
G_{0} / H_{\text {bottom }} & \text { at the lower surface }\end{cases}
\end{aligned}
$$

[44] Where $\mathrm{c}$ is ice heat capacity $(\mathrm{J} / \mathrm{kg} / \mathrm{K}), T$ is ice temperature $(\mathrm{K}), \kappa$ is ice thermal conductivity $(\mathrm{W} / \mathrm{K} / \mathrm{m})$, and $\sigma_{\text {eff }}$ is effective stress $(\mathrm{Pa})$. Here $G$ is ground heat flux and $G_{0}$ is geothermal heat flux $\left(\mathrm{W} / \mathrm{m}^{2}\right)$. The $H$ parameters are depths at which heat fluxes are absorbed by the media. The right hand side is the volumetric heating rate $\left(\mathrm{W} / \mathrm{m}^{3}\right)$. Inside the ice domain, the volumetric heating rate equals the "strain heating", or the converting of work done by gravity into heat used to heat the sliding material or cause a phase change. At the upper and lower boundaries, the volumetric heating rates are respectively the flux divergence/convergence of ground heat flux and geothermal heat flux.

[45] The dynamic (equation (A1)) and thermodynamic (equation (A8)) equations are coupled. The upper boundary condition for equation (A1) is that of free stress. The lateral boundary setting refers to the high-resolution phase mask, which is a 3-D array indicating if a physical volume is occupied by ice, air, water, or soil/rock. The zero-velocitygradient is applied as lateral boundary condition for ice adjacent to air or water. For ice that is adjacent to soil/rock in a certain direction, zero velocity is set normal to this direction.

[46] An energy balance-based land surface scheme (i.e., SHEELS) inside SEGMENT-ice also runs on the same vertical stretching grids but for only the top $10 \mathrm{~m}$ vertical domain. As an energy-balance based land surface scheme, the purpose of SHEELS is to estimate the fluxes (latent, sensible, and ground heat fluxes) between the atmosphere and the ground. The input parameters are air pressure, temperature, and specific humidity ( $2 \mathrm{~m}$ about ground), ice surface temperature, wind speed, and all components of radiation fluxes. These parameters are available from reanalysis data and also are the parameters slated as the highest priority output fields in the Coupled Model Intercomparison Project (CMIP) of the IPCC AR4 archives. It partitions the precipitation into runoff, infiltration, and ponding. It solves essentially the same thermal equation (equation (A8)) for ice temperature and estimates the phase change of ice. Given that the temperature solving is one of the most time consuming processes, SHEELS runs on the same vertical stretching grids but for only the top $10 \mathrm{~m}$ of the vertical domain and takes its temperature values from equation (A8). As applied to the GrIS, SHEELS is responsible for diagnosing surface melt, meltwater refreezing, and topographic-dependent runoff. In case of surface snow cover, a novel layered snow scheme (similar to Mernild et al. [2010]) in SHEELS is activated that evaluates the snow accumulation, metabolism, and aging. Phase changes are estimated according to enthalpy changes. For example, for grids reaching the melting point, extra energy input are used to estimate how much ice is transformed into water. The used energy is reflected on the right hand side forcing 


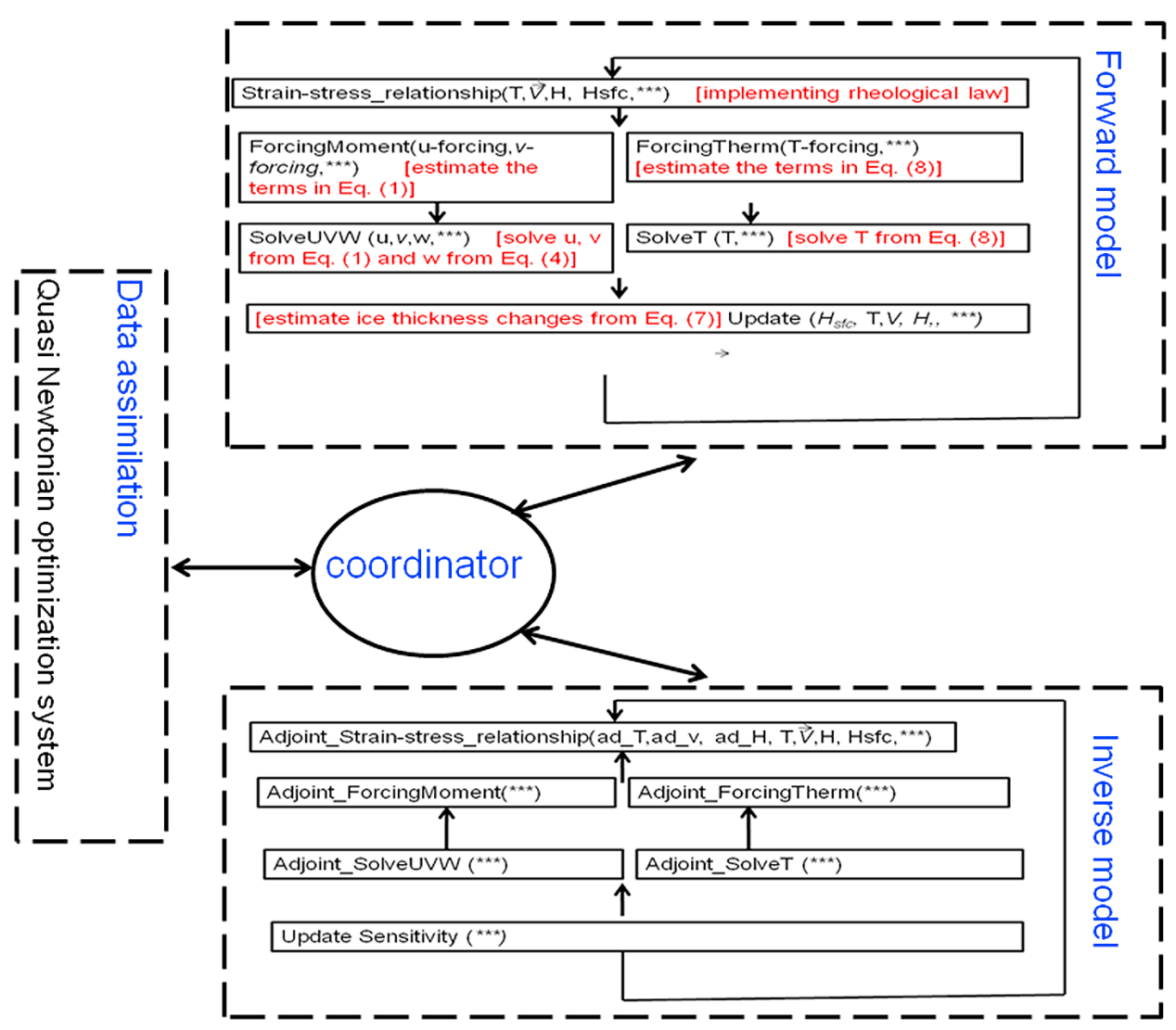

Figure A2. Diagram of the ice dynamic model (SEGMENT-ice). The inverse is constructed based on the forward model (regular ice model) using a line-by-line transformation technique. Both forward and inverse models are used by the data assimilation module to retrieve uncertain model parameters. A quasi-Newton optimization scheme is used in the data assimilation driver.

term $(\dot{Q})$ in equation (A8) for the next time step temperaturesolving. Schematically, the ice model can be represented as in Figure A2.

[47] Ice viscosity depends on temperature and strain rate (Figure A1a). An ice model thus needs to represent strain stage and ice temperature. For our time frame of interest (i.e., the transient climate change period of several hundred years), the largest ice temperature fluctuation is near the upper surface. The stain rate, however, can be large near bottom and/or near the surface (e.g., when the surface air temperature quickly warms up, strain rates can be large near the upper surface). Instead of uniformly increasing the model layer number to better represent vertical ice profile, SEGMENT-ice, to be efficient, uses a vertically stretched grid stencil that better differentiates both bottom and near surface ice domain (Figure A1b). There are 31 vertically stretched layers in delineating the ice thickness, including one lithosphere layer at the bottom, and possibly an adjacent granular layer immediately above it. The vertical ice layers are finer near the upper and lower boundaries but coarser in between, according to a hyperbolic tangent stretching function. As a result, the uppermost layer is merely $1.0 \mathrm{~m}$ thick near the summit, fine enough to accurately simulate the upper surface energy state on monthly time scale for most of the ice surface. The importance of using stretched vertical grid is being realized by the ice modeling community. For example, Bueler and Brown [2009] finely divide the bottom ice domain because the strain rates arguably are larger near the lower boundary. Vertical stretching also facilitates using energy balance based surface melting and runoff schemes.

[48] After spinup (discussed below), the time step for the ice dynamics and thermodynamics integration is 1 day, with atmospheric forcing updated every month. This temporal configuration allows an examination of surface melting extent because melting is seasonal. With an annual time step, as in most paleoclimate studies, it is impossible to resolve this dynamic feature of melt surface area, which is a sensitive index of climate warming. The nonfractured bedrock is given a viscosity of $8 \times 10^{20} \mathrm{~Pa} \cdot \mathrm{s}$, close to the values for crust material. For the timescales of interest here, using a spatially varying viscosity value for bedrock (e.g., estimated from the Greenland geology map) does not affect our results and conclusions. Bedrock requires a viscosity value as the simulations cover a domain that includes bedrock, ice, and water, unlike many models that assume bedrock is static.

[49] In contrast to a recent full Stokes model [Zwinger et al., 2007], which uses finite element numerics, a finite difference technique is used to discretize the governing equations in SEGMENT-ice. SEGMENT-ice uses a staggered Arakawa C-grid stencil so that mass (and other scalars) and velocity components are interlaced. The vertical grid is terrain following $\sigma$-coordinate [Greve and Blatter, 2009, chapter 5] with stretching and horizontal tip-end 


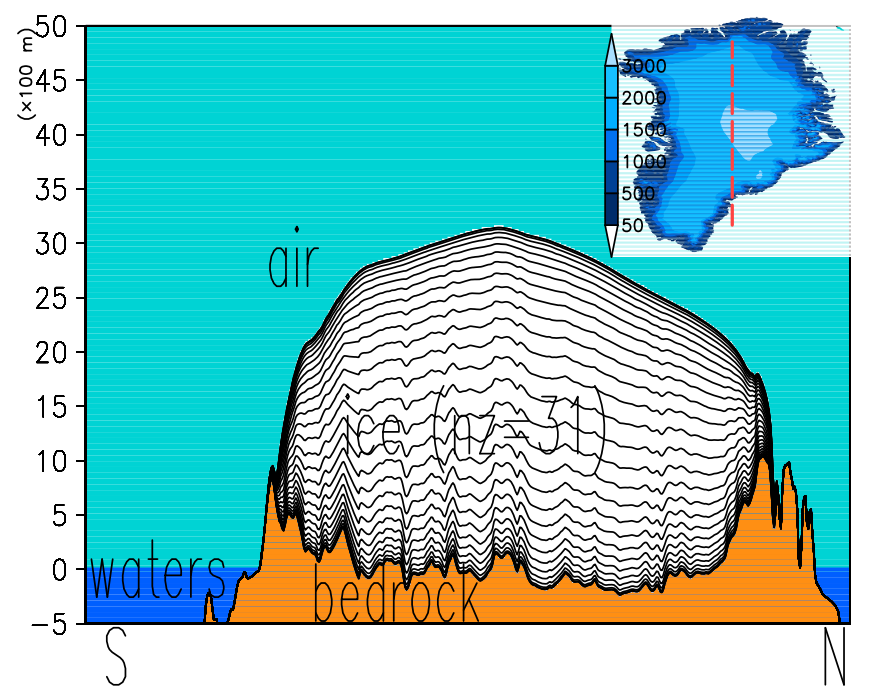

Figure A3. The vertical stretching of a terrain-following sigma coordinate system with horizontal tip-end augmentation is shown, as used in SEGMENT-ice. A cross-section is shown along the $40^{\circ} \mathrm{W}$ meridian (the red dashed line in the inset) of the full simulation domain. Also shown is a crosssection of the three dimensional "phase mask", indicating whether a grid is water, bedrock, ice, or air. All data are from zero time (initial time). Within the time integration period, the "phase mask", ice geometry, and ice temperatures all are updated regularly.

augmentation (Figure A3). The augmentation results in a 3-D "phase mask" (the color shading in Figure A3) that facilitates setting and updating the lateral boundary conditions. Although not activated in this study, the horizontal mesh is adaptive so a finer mesh can be used at the margins where there are steep slopes. We solve for the $u$ and $v$ components explicitly and the $\mathrm{w}$ component is derived from the continuity equation. The ice thickness and surface topography are updated as ice geometry changes in response to precipitation, surface melt, and flow divergence/convergence, according to equation (A7). To effectively reduce numerical noise, an Asselin [1972] time filter is used with a coefficient of 0.1 .

[50] It is critical to obtain a steady flow, in agreement with the ice geometry and temperature regime, before applying the transient climate forcing to project the future state of the ice sheet. The following spinup strategy is used, starting from a zero velocity field at the given ice geometry and temperature field. Because we are dealing with full NavierStokes code in combination with a shear-thinning rheological law, it is important to set a suitable asymptote viscosity for grid points with effective strain rate less than $10^{-8} \mathrm{~s}^{-1}$. All rheological relationships proposed are based on experimental shear-strain diagrams. However, because laboratory ice mechanics experiments must be finished at reasonable time span, it currently lacks a shear-strain diagram extending to the very small strain rate regime. We set the viscosity for those "still" grids to $\left(1-T / T_{p}\right)^{1 / 5} \times 10^{14} \mathrm{~Pa} \bullet \mathrm{s}$, with $T_{p}$ being the pressure melt temperature. As integration continues, effective strain rate will be greater than $10^{-8} \mathrm{~s}^{-1}$ and regular parameterization of the viscosity will be activated. Depending on the detailed numerics, the exact number of integrations may vary significantly; however, the general scene is that the bottom layer reaches stability first and gradually the shallower layer reaches steady state. Upon reaching a steady flow field, the dynamics and thermodynamics and the evolution of the free surface are solved in a fully thermomechanically coupled manner. For any natural body of ice on a slope, there is no true balance of the flow field with the ice geometry, the temperature field, and the surface mass balance. However, there is a constant flow field adjustment toward a balance. To maintain a true steady flow field, the dynamic mass balance must exactly balance the surface mass balance on grid point by grid point basis, and there must be a mechanism to keep the temperature field steady. Thus the spinup scheme assumes the surface meteorological forcing generated surface mass balance (SM) is in perfect balance with the flow divergence/convergence caused dynamic mass balance at every grid point during the spinup period. The temperature field also is assumed steady during the spinup process. Once a steady flow field is obtained, all variables are allowed to vary according to the governing equations, in response to the forcing by the surface atmosphere time series.

[51] SEGMENT-ice has an adjoint-based four-dimensional variational data assimilation component (4D-Var), described by Ren [2004, 2010], Schoof [2006], Gillet-Chaulet and Durand [2010], and Morlighem et al. [2010]. The adjointbased data assimilation system optimally deduces the granular layer properties, such as particle size, total granular material thickness, and the upper/lower bounding inertial numbers, constrained by present ice sheet flow field, thermal structure, and geometry (Figure A2).

[52] Acknowledgments. This work was supported by the Gary Comer Science Foundation. We thank R. Alley for providing the GISP2 borehole data, R. Greve for offering the SICOPOLIS model code, and C. Van der Veen for providing the force balance model code. The first author also thanks K. Jezek for his insightful comments on the possible importance of the advection and inertial terms for the ice flow model. S. Otsu help provided the NASA-JPL images of observed surface velocity. Molly McAllister from NSIDC provided technical assistance in using the remote sensing data. Transient climate simulations under SRES A1B were obtained from the PCMDI/CMIP project. Finally, we wish to thank two anonymous reviewers for numerous comments that have helped greatly in improving the final version of the manuscript.

\section{References}

Abdalati, W., and K. Steffen (1997), Snowmelt on the Greenland Ice Sheet as derived from passive microwave satellite data, J. Clim., 10, 165-175, doi:10.1175/1520-0442(1997)010<0165:SOTGIS $>2.0 . C O ; 2$.

Alley, R. (1993), In search of ice-stream sticky spots, J. Glaciol., 39, $447-454$.

Alley, R. (2000), Ice-core evidence of abrupt climate changes, Proc. Natl. Acad. Sci. U. S. A., 97, 1331-1334, doi:10.1073/pnas.97.4.1331.

Alley, R., T. Dupont, B. Parizek, S. Anandakrishnan, D. Lawson, G. Larson, and E. Evenson (2005), Outburst flooding and initiation of ice-stream surges in response to climatic cooling: A hypothesis, Geomorphology, 75, 76-89.

ACIA (2005), Arctic Climate Impact Assessment, Cambridge Univ. Press, Cambridge, U. K.

Ashcraft, I. S., and D. Long (2006), Comparison of methods for melt detection over Greenland using active and passive microwave measurements, Int. J. Remote Sens., 27, 2469-2488, doi:10.1080/01431160500534465. Asselin, R. (1972), Frequency filter for time integrations, Mon. Weather Rev., 100, 487-490, doi:10.1175/1520-0493(1972)100<0487: FFFTI $>2.3 . \mathrm{CO} ; 2$.

Bamber, J., S. Ekholm, and W. Krabill (2001), A new, high-resolution digital elevation model of Greenland fully validated with airborne laser altimeter data, J. Geophys. Res., 106, 6733-6745, doi:10.1029/ 2000JB900365. 
Benson, C. (1962), Stratigraphic studies in the snow and firn of the Greenland ice sheet, Rep. 70, Snow Ice and Permafrost Res. Estab. Hanover, N. H.

Bindschadler, R. (1983), The importance of pressurized subglacial water in separation and sliding at the glacier bed, J. Glaciol., 29, 3-19.

Bueler, E., and J. Brown (2009), Shallow shelf approximation as a "sliding law" in a thermo-mechanically coupled ice sheet model, J. Geophys. Res., 114, F03008, doi:10.1029/2008JF001179.

Burrough, P. A., and R. A. McDonnell (2004), Principles of Geographical Information Systems: Spatial Information Systems and Geostatistics, Oxford Univ. Press, Oxford, U. K

Chen, J., C. Wilson, and B. Tapley (2006), Satellite gravity measurements confirm accelerated melting of Greenland ice sheet, Science, 313, 1958-1960, doi:10.1126/science. 1129007.

Collins, W., et al. (2007), The community climate system model: CCSM3, J. Climate, 19, 2122-2143.

Crosson, W., C. Laymon, R. Inguva, and M. Schamschula (2002), Assimilating remote sensing data in a surface flux-soil moisture model, Hydrol. Process., 16, 1645-1662, doi:10.1002/hyp.1051.

Cuffey, K., G. Clow, R. Alley, M. Stuiver, E. Waddington, and R. Saltus (1995), Large arctic temperature change at the Wisconsin-Holocene glacial transition, Science, 270, 455-458, doi:10.1126/science. 270 . 5235.455.

Durham, W. B., S. H. Kirby, and L. A. Stern (1992), Effects of dispersed particulates on the rheology of water ice at planetary conditions, J. Geophys. Res., 97, 20,883-20,897, doi:10.1029/92JE02326.

Engelhardt, H., and B. Kamb (1998), Basal sliding of Ice Stream B, West Antarctica, J. Glaciol., 44, 223-230.

Ettema, J., M. R. van den Broeke, E. van Meijgaard, W. J. van den Berg, J. L. Bamber, J. E. Box, and R. C. Bales (2009), Higher surface mass balance of the Greenland ice sheet revealed by high-resolution climate modeling, Geophys. Res. Lett., 36, L12501, doi:10.1029/2009GL038110.

Fahnestock, M., R. Bindschadler, R. Kwok, and K. Jezek (1993), Greenland ice sheet surface properties and ice dynamics from ERS-1 SAR imagery, Science, 262, 1530-1534, doi:10.1126/science.262. 5139.1530

Fausto, R., A. Ahlstrom, D. van As, C. Boggild, and S. Johnsen (2009) A new present-day temperature parameterization for Greenland, J. Glaciol., 55, 95-105, doi:10.3189/002214309788608985.

Gillet-Chaulet, F., and G. Durand (2010), Glaciology: Ice-sheet advance in Antarctica, Nature, 467(7317), 794-795, doi:10.1038/467794a.

Gilpin, R. (1979), A model of the "liquid-like" layer between ice and a substrate with applications to wire regelation and particle migration, J. Colloid Interface Sci., 68, 235-251, doi:10.1016/0021-9797(79) 90277-7.

Glen, J. (1955), The creep of polycrystalline ice, Proc. R. Soc. London, Ser. A, 228, 519-538, doi:10.1098/rspa.1955.0066.

Goldsby, D., and D. Kohlstedt (2001), Superplastic deformation of ice: Experimental observations, J. Geophys. Res., 106, 11,017-11,030, doi:10.1029/2000JB900336.

Greve, R. (2000), On the response of the Greenland ice sheet to greenhouse climate change, J. Clim. Change, 46, 289-303, doi:10.1023/ A:1005647226590.

Greve, R. (2005), Relation of measured basal temperatures and the spatial distribution of the geothermal heat flux for the Greenland ice sheet, Ann. Glaciol., 42, 424-432, doi:10.3189/172756405781812510.

Greve, R., and H. Blatter (2009), Dynamics of Ice Sheets and Glaciers, Adv. in Geophys. and Environ. Mech. and Math., 287 pp., Springer, New York.

Greve, R., and K. Hutter (1995), Polythermal three-dimensional modelling of the Greenland ice sheet with varied geothermal heat flux, Ann. Glaciol., $21,8-12$.

Greve, R., and S. Otsu (2007), The effect of north-east ice stream on the Greenland ice sheet in changing climates, Cryosphere Discuss., 1 , 41-76, doi:10.5194/tcd-1-41-2007.

Hallet, B. (1996), Glacial quarrying: A simple theoretical model, Ann. Glaciol., 22, 1-9.

Hooke, R. (1981), Flow law for polycrystalline ice in glaciers: Comparison of theoretical predictions, laboratory data, and field measurements, Rev. Geophys., 19, 664-672, doi:10.1029/RG019i004p00664.

Hooke, R., and N. Iverson (1985), experimental study of ice flow around a bump: Comparison with theory, Geogr. Ann., 67, 187-197, doi:10.2307/ 521097.

Howat, I. M., I. Joughin, and T. A. Scambos (2007), Rapid changes in ice discharge from Greenland outlet glaciers, Science, 315(5818), 1559-1561, doi:10.1126/science.1138478.

Huybrechts, P., J. Gregory, I. Janssens, and M. Wild (2004), Modelling Antarctic and Greenland volume changes during the 20th and 21st centuries forced by GCM time slice integrations, Global Planet. Change, 42(1-4), 83-105, doi:10.1016/j.gloplacha.2003.11.011.

Jop, P., Y. Forterre, and O. Pouliquen (2006), A constitutive law for dense granular flows, Nature, 441, 727-730, doi:10.1038/nature04801.

Joughin, I., I. Howat, R. B. Alley, G. Ekstrom, M. Fahnestock, T. Moon, M. Nettles, M. Truffer, and V. C. Tsai (2008), Ice-front variation and tidewater behavior on Helheim and Kangerdlugssuaq Glaciers, Greenland, J. Geophys. Res., 113, F01004, doi:10.1029/2007JF000837. Joughin, I., B. Smith, I. Howat, T. Scambos, and T. Moon (2010), Greenland flow variability from ice-sheet-wide velocity mapping, J. Glaciol., 56, 415-430.

K-1 Model Developers (2004), K-1 coupled GCM (MIROC) description, Tech. Rep. 1, edited by H. Hasumi and S. Emori, Cent. for Clim. Syst. Res, Tokyo.

Kalnay, E., et al. (1996), The NCEP/NCAR 40-Year Reanalysis Project, Bull. Am. Meteorol. Soc., 77, 437-471, doi:10.1175/1520-0477(1996) 077<0437:TNYRP $>2.0 . \mathrm{CO} ; 2$.

MacAyeal, D. (1992), Irregular oscillations of the west Antarctic ice sheet, Nature, 359, 29-32, doi:10.1038/359029a0.

Maslanik, J., and J. Stroeve (2007), DMSP SSM/I daily polar gridded brightness temperature, 1987-2007, digital media Natl. Snow and Ice Data Cent, Boulder, Colo.

Mernild, S., G. Liston, C. Hiemstra, and J. Christensen (2010), Greenland Ice Sheet Surface Mass-Balance Modeling in a 131-Yr Perspective, 1950-2080, J. Hydrometeorol., 11, 3-25, doi:10.1175/2009JHM1140.1. Morlighem, M., E. Rignot, H. Seroussi, E. Larour, H. Ben Dhia, and D. Aubry (2010), Spatial patterns of basal drag inferred using control methods from a full-Stokes and simpler models for Pine Island Glacier, West Antarctica, Geophys. Res. Lett., 37, L14502, doi:10.1029/ 2010GL043853.

Mote, T. L. (2007), Greenland surface melt trends 1973-2007: Evidence of a large increase in 2007, Geophys. Res. Lett., 34, L22507, doi:10.1029/ 2007GL031976.

Nakicenovic, N., and R. Swart (Eds.) (2000), Special Report on Emissions Scenarios (SRES), 612 pp., Cambridge Univ. Press, New York.

Nettles, M., et al. (2008), Step-wise changes in glacier flow speed coincide with calving and glacial earthquakes at Helheim Glacier, Greenland, Geophys. Res. Lett., 35, L24503, doi:10.1029/2008GL036127.

Oerlemans, J. (2001), Glaciers and Climate Change, 148 pp., A.A. Balkema, Lisse, Netherlands.

Ohmura, A., and N. Reeh (1991), New precipitation and accumulation maps for Greenland, J. Glaciol., 37, 140-148.

Ohmura, A., M. Wild, and L. Bengtsson (1996), A possible change in mass balance of Greenland and Antarctica ice sheets in the coming century, J. Clim., 9, 2124-2136, doi:10.1175/1520-0442(1996)009<2124:APCIMB> 2.0.CO;2.

Paterson, W. (1994), The Physics of Glaciers, 3rd ed., Pergamon, New York

Pattyn, F. (2003), A new three-dimensional higher-order thermomechanical ice sheet model: Basal sensitivity, ice stream development, and ice flow across subglacial lakes, J. Geophys. Res., 108(B8), 2382, doi:10.1029/ 2002JB002329

Pattyn, F., et al. (2008), Benchmark experiments for higher-order and fullStokes ice sheet models (ISMIP-HOM), Cryosphere, 2, 95-108, doi: $10.5194 /$ tc-2-95-2008

Peng, G., L. Leslie, and Y. Shao (2002), Environmental Modeling and Prediction, 480 pp., Springer, New York.

Pollack, H., S. Hurter, and J. Johnson (1993), Heat flow from the Earth's interior: Analysis of the global data set, Rev. Geophys. 31, 267-280.

Ren, D. (2004), 4D-Var retrieval of prognostic land surface model variables, Ph.D. thesis, Univ. of Oklahoma, Norman, Okla.

Ren, D. (2010), Adjoint retrieval of prognostic land surface model variables for an NWP model: Assimilation of ground surface temperature, Cent. Eur. J. Geosci., 2, 83-102, doi:10.2478/v10085-009-0043-2.

Ren, D., D. Karoly, and L. M. Leslie (2007), Mountain glacier melting rate for the period 2001-2030 estimated from three CGCM simulations for the Greater Himalayas, J. Appl. Meteorol. Climatol., 46, 890-899, doi:10.1175/JAM2499.1.

Ren, D., L. M. Leslie, and D. Karoly (2008), Landslide risk analysis using a new constitutive relationship for granular flow, Earth Interact., 12, 1-16, doi:10.1175/2007EI237.1

Ren, D., R. Fu, D. Karoly, L. Leslie, J. Chen, and C. Wilson (2010), A new ice sheet model validated by remote sensing of the Greenland ice sheet, Cent. Eur. J. Geosci., 2, 501-513, doi:10.2478/v10085-010-0012-9.

Rignot, E., and P. Kanagaratnam (2006), Changes in the velocity structure of the Greenland ice sheet, Science, 311, 986-990, doi:10.1126/science. 1121381 .

Schoof, C. (2006), A variational approach to ice stream flow, J. Fluid Mech., 556, 227-251, doi:10.1017/S0022112006009591. 
Shreve, R. (1984), Glacier sliding at subfreezing temperatures, J. Glaciol., 30, 341-347.

Smith, E., W. Crosson, H. Cooper, and H. Weng (1993), Estimation of surface heat and moisture fluxes over a prairie grassland. Part III: Design of a hybrid physical/remote sensing biosphere model, J. Geophys. Res., 98, 4951-4978, doi:10.1029/92JD01907.

Solomon, S., D. Qin, M. Manning, Z. Chen, M. Marquis, K. B. Averyt, M. Tignor, and H. L. Miller (Eds.) (2007), Climate Change 2007: The Physical Science Basis. Contribution of Working Group I to the Fourth Assessment Report of the Intergovernmental Panel on Climate Change, 996 pp., Cambridge Univ. Press, New York.

Van den Broeke, M., P. Smeets, J. Ettema, C. van der Veen, R. van de Wal, and J. Oerlemans (2008), Partitioning of melt energy and meltwater fluxes in the ablation zone of the west Greenland ice sheet, Cryosphere, 2, 179-189, doi:10.5194/tc-2-179-2008.

Van den Broeke, M., J. Bamber, J. Ettema, E. Rignot, E. Schrama, W. van de Berg, E. van Meijgaard, I. Velicogna, and B. Wouters (2009), Partitioning recent Greenland mass loss, Science, 326, 984-986, doi:10.1126/science. 1178176.

Van der Veen, C., and I. Whillans (1989), Force budget: I. Theory and numerical methods, J. Glaciol., 35, 53-60, doi:10.3189/002214389793701581.

Velicogna, I., and J. Wahr (2006), Acceleration of Greenland ice mass loss in spring 2004, Nature, 443, 329-331, doi:10.1038/nature05168.

Wang, W., and R. Warner (1999), Modelling of anisotropic ice flow in Law Dome, East Antarctica, Ann. Glaciol., 29, 184-190, doi:10.3189/ 172756499781820932.

Weertman, J. (1957), On the sliding of glaciers, J. Glaciol., 3, 33-38.

Weertman, J. (1983), Creep deformation of ice, Annu. Rev. Earth Planet. Sci., 11, 215-240, doi:10.1146/annurev.ea.11.050183.001243.
Wouters, B., D. Chambers, and E. Schrama (2008), GRACE observes small-scale mass loss in Greenland, Geophys. Res. Lett., 35, L20501, doi:10.1029/2008GL034816.

Yin, J., M. Schlesinger, and R. Stouffer (2009), Model projections of rapid sea-level rise on the northeast coast of the United States, Nat. Geosci., 2, 262-266, doi:10.1038/ngeo462.

Zwally, H., and M. Giovinetto (2001), Balance mass flux and ice velocity across the equilibrium line in drainage systems of Greenland, J. Geophys. Res., 106, 33,717-33,728, doi:10.1029/2001JD900120.

Zwally, H., W. Abdalati, T. Herring, K. Larson, J. Saba, and K. Steffen (2002), Surface melt-induced acceleration of Greenland ice-sheet flow, Science, 297, 218-222, doi:10.1126/science.1072708.

Zwinger, T., and J. Moore (2009), Diagnostic and prognostic simulations with a full Stokes model accounting for superimposed ice of Midtre Lov'enbreen, Svalbard, Cryosphere, 3, 217-229.

Zwinger, T., R. Greve, O. Gagliardini, T. Shiraiwa, and M. Lyly (2007), A full Stokes flow thermo-mechanical model for firn and ice applied to Gorshkov crater glacier, Kamchatka, Ann. Glaciol., 45, 29-37, doi: $10.3189 / 172756407782282543$

J. Chen, R. Fu, and C. Wilson, Department of Geological Sciences, Jackson School of Geosciences, University of Texas at Austin, 1 University Station C1100, Austin, TX 78712, USA

D. J. Karoly, School of Earth Sciences, University of Melbourne, Melbourne, VIC 3010, Australia.

L. M. Leslie, School of Meteorology, University of Oklahoma, Norman, OK 73019, USA.

D. Ren, Australian Sustainable Development Institute, Curtin University, Perth, WA 6845, Australia. (DiandongRen1972@mail.utexas.edu) 


\section{University Library}

\section{- M M N E R VA A gateway to Melbourne's research publications}

Minerva Access is the Institutional Repository of The University of Melbourne

Author/s:

Ren, Diandong;FU, RONG;Leslie, Lance M.;Karoly, David J.;Chen, Jianli;Wilson, Clark

Title:

A multirheology ice model: formation and application to the Greenland ice sheet

Date:

2011

Citation:

Ren, D., Fu, R., Leslie, L. M., Karoly, D. J., Chen, J. L., \& Wilson, C. (2011). A multirheology ice model: formulation and application to the Greenland ice sheet. Journal of Geophysical Research, 116, doi: 10.1029/2010JD014855.

Publication Status:

Published

Persistent Link:

http://hdl.handle.net/11343/32750 